\title{
Effect of basalt fibre hybridisation and sizing removal on mechanical and thermal properties of hemp fibre reinforced HDPE composites
} \author{
Nina Graupner ${ }^{\mathrm{c}}$ \\ ${ }^{a}$ Department of Chemical Engineering Materials Environment, Sapienza-Università di Roma, Roma, Italy \\ ${ }^{\mathrm{b}}$ Elettra Sincrotrone Trieste, Area Science Park, Trieste, Italy \\ ${ }^{\mathrm{c}}$ The Biological Materials Group, Department of Biomimetics, HSB - City University of Applied Sciences, Bremen, Germany
}

Fabrizio Sarasini ${ }^{\mathrm{a}, *}$, Jacopo Tirillò ${ }^{\mathrm{a}}$, Claudia Sergi ${ }^{\mathrm{a}}$, Maria Carolina Seghini ${ }^{\mathrm{a}}$, Luca Cozzarini ${ }^{\mathrm{b}}$,

\section{A R T I C L E I N F O}

\section{Keywords:}

Polymer-matrix composites

Natural fibres

Basalt fibres

Hybrid

Interface/interphase

\begin{abstract}
A B S T R A C T
Despite the advantages offered by natural fibre-based thermoplastic composites in terms of environmental impact and cost, their mechanical performance is generally lower than that of synthetic counterparts. Hybridisation with mineral fibres (basalt) can broaden the industrial applications of natural fibre reinforced composites. The present study focused on the performance of injection-moulded short basalt fibre, hemp fibre and hemp/basalt fibre hybrid high density polyethylene (HDPE) composites. Effects of a maleated coupling agent on the thermal and mechanical properties of the resulting composites were evaluated as a function of the fibre mass fraction. Hybridisation of hemp fibres with basalt fibres was found to significantly increase the mechanical properties and the crystallinity of hemp-fibre reinforced composites thus suggesting that short hemp/basalt fibre hybrid HDPE composites are promising candidates for semi-structural applications. Additionally, a sizing removal procedure mimicking the conditions experienced in an end-of-life composite thermal recycling process was defined and discussed in terms of residual mechanical properties of basalt/HDPE composites.
\end{abstract}

\section{Introduction}

It is well known that materials have permitted the development of mankind since the very beginning and no technological advancement is possible without suitable materials able to support it. Besides materials and their specific properties (thermal, mechanical, electrical and so forth), other fundamental factors that need to be taken into account include the environmental aspects of their production, use, disposal at end of life in an attempt to reduce adverse impact. It is worth mentioning how, over the years, our dependence gradually shifted from a reliance on renewable materials to one that depends on materials that use resources not easily replaceable [1]. Nowadays this trend is reversed due to a greater awareness of global resource depletion which triggered the exploration of new ways to use materials as environmental prerogatives became more and more pressing. In this framework, the use of lightweight, low cost natural fibres offers the potential to replace glass fillers in several applications [2]. For the last two decades, thermoplastic as well as thermoset-based natural fibre reinforced composites (NFCs) have experienced a tremendous growth especially in the automotive industry for door panels, seat backs, headliners, package trays, dashboards, and interior parts $[3,4]$.
According to a recent market report released by Lucintel [5], the global natural fibre composite materials market is forecast to grow at a Compound Annual Growth Rate (CAGR) of 8.2\% from 2015 to 2020. Interest in bio-based materials, and specifically, natural fibre reinforced composites, coincides not only with legislation that has been introduced in large markets such as the European Union (Directive 2000/53/EC) but with the priority of many major automakers' interest in global sustainability. A typical vehicle is a very complex environment, characterised by over 40,000 parts, 1000 different materials and 10,000 chemical substances. $75 \%$ is typically represented by metals and $17 \%$ by plastics, elastomers and textiles. As stated in Ford's 17th annual report on sustainability progress, the environmental, economic and performance benefits of using plant-based materials may include reductions in carbon dioxide $\left(\mathrm{CO}_{2}\right)$ emissions, vehicle weight and petroleum consumption; lower manufacturing energy use and costs; reduced pressure on natural resources; keeping waste out of landfill; and the creation of new markets and revenue streams for farmers [6]. Unfortunately, most of these composite materials have received much commercial success in the non-structural (cosmetic) and rarely in semistructural applications mainly because of some technical challenges, such as moisture stability, fibre/polymer interphase

\footnotetext{
* Corresponding author.

E-mail address: fabrizio.sarasini@uniroma1.it (F. Sarasini).
} 
compatibility, and consistent, repeatable fibre sources which are still the subject of intense research across the world. An approach currently used both in research and practical applications is hybridisation, as a means of combining bioresources with conventional materials thus obtaining products with a suitable balance of properties and cost $[7,8]$. From a literature survey, natural fibres are usually hybridised with glass fibres and improved thermal stability, mechanical properties and resistance against water absorption are reported [8]. In this context, the aim of this study is to develop high performance composites based on high density polyethylene using short hemp fibres and basalt fibres as reinforcement, to be used in semistructural applications. Basalt fibres are produced from mineral origin and are rapidly gaining interest as a replacement of E-glass fibres in composite applications due to improved mechanical properties and better thermal resistance that could in principle allow better prospects to survive end of life recycling processes [9]. Both hemp and basalt fibres have been widely investigated as reinforcement in polymer matrices $[9,10]$ but their combination in short fibre reinforced HDPE composites has not been addressed. In vehicles, polymeric materials can be used in interior and exterior parts and among different polymers, polyolefins (polypropylene and high density polyethylene) have experienced a tremendous growth in the automotive industry due to their excellent cost-performance ratio, low density, great weathering and abrasion resistance, and good chemical resistance. Recently Lu and Oza [11] investigated hemp fibre reinforced composites based on recycled high density polyethylene (rHDPE) and virgin high density polyethylene (vHDPE). In order to increase fibre/ matrix compatibility, hemp fibres were treated with $5 \mathrm{wt} \% \mathrm{NaOH}$. The results showed that the mechanical properties of hemp-rHDPE composites were compatible with, or even higher than those of hemp-vHDPE composites. The same authors in [12] studied the thermal stability of HDPE/hemp composites where the fibres were subjected to two different chemical treatments, with $\mathrm{NaOH}$ and a silane solution (triethoxyvinylsilane). Both silane and $\mathrm{NaOH}$ treatment were reported to improve the thermal stability of the resulting composites, but silane treated hemp-HDPE composites exhibited superior thermal stability due to a better interphase. As regards basalt fibres, several works have confirmed their potentialities to replace glass fibres [13-19], but from these studies clearly emerged the need to increase, also for basalt fibres, the interfacial adhesion with the polymeric matrix. In the present study the effect of a compatibilising agent, namely maleic anhydride grafted high density polyethylene (MAPE), on the mechanical and thermal properties of hemp, basalt and their hybrid composites has been studied. In addition, the level of interfacial adhesion of two commercially available basalt fibres with different sizings has been assessed through single fibre fragmentation tests (SFFT) in order to select the optimal basalt fibre for HDPE reinforcement. In an attempt to shed light on possible synergic effects between basalt fibre sizing and maleic anhydride grafted high density polyethylene coupling agent, some composite formulations were also manufactured with basalt fibres previously subjected to a sizing removal process based on a combination of acetone treatment and high temperature exposure. These results are reported for the first time for a HDPE/basalt system.

\section{Materials and methods}

\subsection{Materials}

Injection moulding grade HDPE type Eraclene MP90 (Melt Flow Rate at $190{ }^{\circ} \mathrm{C} / 2.16 \mathrm{~kg}$ of $7 \mathrm{~g} / 10 \mathrm{~min}$ and density of $0.96 \mathrm{~g} / \mathrm{cm}^{3}$ ) from Eni Polimeri Europa (Mantova, Italy) was used as matrix, while chopped basalt fibres were provided by Incotelogy $\mathrm{GmbH}$ (Pulheim, Germany). The average diameter of the fibres was $13 \mu \mathrm{m}$ with a nominal length of $3.2 \mathrm{~mm}$. One type of fibres was surface modified with a silane sizing optimsed for epoxy resins (Bas-EP) while the other type was modified with a sizing compatible with thermoplastics (Bas-PP), in particular polypropylene. Hemp composites were produced using a commercially available compound of HDPE loaded with $30 \mathrm{wt} \%$ of hemp fibres supplied by AFT Plasturgie (Fontaine les Dijon, France). This masterbatch was then diluted with neat HDPE to obtain additional formulations. In order to tailor the fibre/matrix interphase, some basalt, hemp and hybrid formulations were also produced using a coupling agent. The matrix was modified by addition of $5 \mathrm{wt} \%$ Polybond 3009 supplied by Addivant Corporation (Danbury, USA), which is a standard maleic anhydride modified high density polyethylene (MAPE) with a high (0.8-1.2\%) maleic anhydride content (Melt Flow Rate at $190^{\circ} \mathrm{C} /$ $2.16 \mathrm{~kg}$ of $5 \mathrm{~g} / 10 \mathrm{~min}$ and density of $0.95 \mathrm{~g} / \mathrm{cm}^{3}$ ).

Some basalt fibres with sizing optimised for thermoplastics were also submitted to a soxhlet extraction in acetone, to assess the stability of the sizing, in accordance with a previous study [20]. In particular, fibres were subjected only to acetone extraction ( $24 \mathrm{~h}$ ) and also to a combination of acetone extraction and thermal exposure in air at $\mathrm{T}=400{ }^{\circ} \mathrm{C}$ for $4 \mathrm{~h}$ in an attempt to remove both the physisorbed and covalently bound components of the sizing.

\subsection{Fibre tensile test}

A Fafegraph M testing machine (Textechno, Mönchengladbach, Germany) working with a load cell of $100 \mathrm{cN}$ was used for the tensile tests. The machine was equipped with pneumatic clamps covered with hard PVC. The gauge length was set to $20 \mathrm{~mm}$ at a testing speed of $10 \mathrm{~mm} / \mathrm{min}$. A clamp with a mass of $50 \mathrm{mg}$ was used for pre-tensioning the fibres. 25 fibres for each basalt type were tested.

\subsection{Single fibre fragmentation test (SFFT) of basalt fibres}

In order to assess the actual fibre/matrix adhesion of Bas-EP and Bas-PP fibres in a HDPE matrix, a single fibre fragmentation test (SFFT) was used [21]. In this case basalt fibres were carefully extracted from basalt rovings of the same type used for composite manufacture. For sample preparation, HDPE sheets with a thickness between 180 and $250 \mu \mathrm{m}$ were produced with a self-manufactured press-rheometer (dimensions of the mould: $15 \times 8 \mathrm{~cm}^{2}$ ) which fits in a Zwick Z020 universal testing machine equipped with a $20 \mathrm{kN}$ load cell (Zwick/Roell GmbH, Ulm, Germany). The temperature of both press plates was set to $190^{\circ} \mathrm{C}$. 3-5 g HDPE granules were spread evenly between two Teflon foils and were inserted into the press-rheometer. In order to melt the granules and to avoid damage of the Teflon foils the plates of the rheometer were compressed to a distance of $10 \mathrm{~mm}$ and held for $1 \mathrm{~min}$. Then the press plates were compacted at a rate of $5 \mathrm{~mm} / \mathrm{min}$ to a pressure of about $4 \mathrm{~N} / \mathrm{cm}^{2}$. In the following, the pressure was heighten to approx. $60 \mathrm{~N} / \mathrm{cm}^{2}$ at a speed of $1 \mathrm{~mm} / \mathrm{min}$. The Teflon foils containing the polymer sheets were removed and cooled between two aluminum plates of a mass of approx. $700 \mathrm{~g}$. Single fibres were oriented, placed on one HDPE sheet and fixed with adhesive tape on both ends. The sheet was covered with a second sheet and was pressed with the press-rheometer to stack the films together (same procedure as described for the polymer sheets but the pressure of $60 \mathrm{~N} / \mathrm{cm}^{2}$ was held for $5 \mathrm{~min}$ ). To determine the critical fragment length and apparent interfacial shear strength (IFSS), the sheets were cut into dumbbell shaped specimens with a width of approx. $3 \mathrm{~mm}$ and a total length of $36 \mathrm{~mm}$. The length of the parallel section was $16 \mathrm{~mm}$. Testing was carried out in a Zwick/Roell universal testing machine (Zwick/Roell, Ulm, Germany) type Z020 operating with a load cell of $500 \mathrm{~N}$ and a testing speed of $0.2 \mathrm{~mm} / \mathrm{min}$. The gauge length was set to $15.5 \mathrm{~mm}$. Before the specimen was broken the test was finished. The fragment length of the individual samples was measured under an optical light microscope Bresser Science ADL 601P with a polariser (Bresser GmbH, Rhede, Germany) using an object micrometer. For the analysis of the fragment length only samples were taken into account where the crack went completely through the fibre (Fig. 1). The measured results allow the calculation of the critical fragment length $L_{f c}$ in $\mathrm{mm}$ according to Eq. (1): 


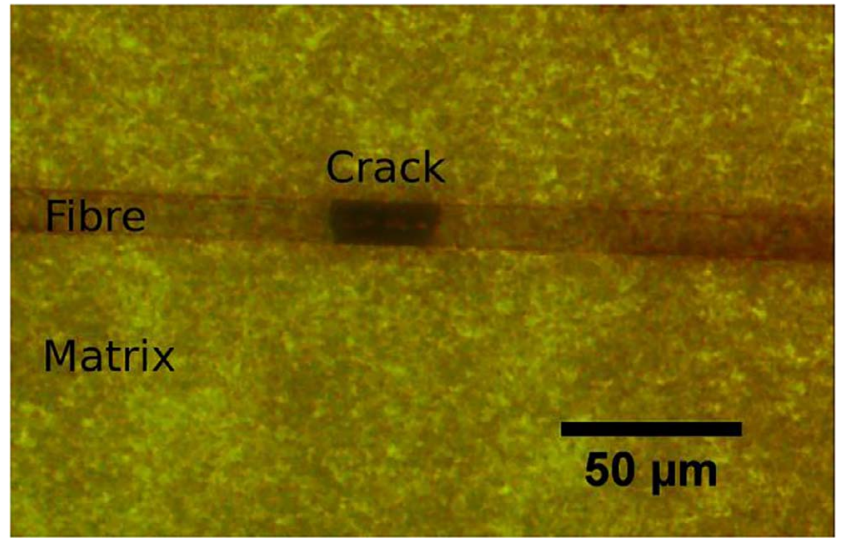

Fig. 1. Typical fragment of a basalt fibre (Bas-PP) in a HDPE matrix.

$L_{f c}=\frac{4}{3} \cdot \bar{l}=\frac{4}{3} \sum_{i=0}^{n} \frac{l_{i}}{n}$

with $\bar{l}=$ average fragment length, $n=$ number of measurements and $l_{i}=$ single fragment length in $\mathrm{mm}$ and the apparent IFSS $\tau$ in N/mm ${ }^{2}$ according to Eq. (2) [22]:

$\tau=\frac{\sigma_{f} \cdot d_{f}}{2 \cdot L_{f c}}$

with $\sigma_{f}=$ tensile strength of the fibre in $\mathrm{N} / \mathrm{mm}^{2}$ and $d_{f}=$ diameter of the fibre in $\mathrm{mm}$.

\subsection{Compounding and processing}

The different formulations produced are summarised in Table 1 . All composites were manufactured through a two-stage process involving extrusion (co-rotating twin-screw extruder, Thermo Scientific Process 11, Thermo Fisher Scientific, Waltham, USA) and injection moulding (Haake MiniJet II Pro, Thermo Fisher Scientific, Waltham, USA). Prior to extrusion, the hemp fibre compound was dried at $115^{\circ} \mathrm{C}$ for $2 \mathrm{~h}$. Two different temperature profiles ( 8 zones) were used for basalt and hemp-based formulations due to different viscosity of the blends, namely 170-180-190-200-200-190-180-180 ${ }^{\circ} \mathrm{C}$ and 150-160-170-180-180-170-160-160 ${ }^{\circ} \mathrm{C}$, respectively. Screw speed was set at $150 \mathrm{rpm}$. The mould during injection moulding (type 1BA

Table 1

Formulation and description of composite samples produced.

\begin{tabular}{lllll}
\hline Designation of samples & $\begin{array}{l}\text { HDPE } \\
(w \mathrm{w} \%)\end{array}$ & $\begin{array}{l}\text { Basalt fibre } \\
(w \mathrm{wt} \%)\end{array}$ & $\begin{array}{l}\text { Hemp fibre } \\
(\mathrm{wt} \%)\end{array}$ & $\begin{array}{l}\text { Coupling agent } \\
(\mathrm{wt} \%)\end{array}$ \\
\hline HDPE10B & 90 & 10 & - & - \\
HDPE20B & 80 & 20 & - & - \\
HDPE30B & 70 & 30 & - & - \\
HDPE40B & 60 & 40 & - & - \\
HDPE10B5MA & 85 & 10 & - & 5 \\
HDPE20B5MA & 75 & 20 & - & 5 \\
HDPE30B5MA & 65 & 30 & - & 5 \\
HDPE40B5MA & 55 & 40 & - & 5 \\
HDPE10H & 90 & - & 10 & - \\
HDPE20H & 80 & - & 20 & - \\
HDPE30H & 70 & - & 30 & - \\
HDPE10H5MA & 85 & - & 10 & 5 \\
HDPE20H5MA & 75 & - & 20 & 5 \\
HDPE30H5MA & 65 & - & 30 & 5 \\
HDPE10H20B & 70 & 20 & 10 & - \\
HDPE15H15B & 70 & 15 & 15 & - \\
HDPE20H10B & 70 & 10 & 20 & - \\
HDPE10H20B5MA & 65 & 20 & 10 & 5 \\
HDPE15H15B5MA & 65 & 15 & 15 & 5 \\
HDPE20H10B5MA & 65 & 10 & 20 & 5 \\
\hline
\end{tabular}

for tensile tests) was heated at $40{ }^{\circ} \mathrm{C}$ while the loading cylinder was kept at $220^{\circ} \mathrm{C}$ for basalt composites and at $180^{\circ} \mathrm{C}$ for hemp and hybrid formulations. The injection procedure included two steps: the injection step at a pressure in the range 350-550 bar depending on the fibre amount for $10 \mathrm{~s}$ and a post injection step at 60 bar for additional $10 \mathrm{~s}$. The same procedure was used to manufacture composites from basalt fibres treated in acetone and those treated in acetone plus thermally treated (TT) in air with and without coupling agent at two different percentages, namely 10 and $30 \mathrm{wt} \%$.

\subsection{Surface and morphological characterisations}

X-ray photoelectron spectroscopy (XPS) measurements on basalt fibre surfaces were carried out with a VG Scientific ESCALAB MKII (Thermo Fisher Scientific, Waltham, USA) spectrometer, operating in fixed analyzer energy mode, with pass energy of $50 \mathrm{eV}$ for survey scans and pass energy $20 \mathrm{eV}$ for high resolution scans. Non-monochromatised $\mathrm{Al} \mathrm{K} \alpha$ exciting radiation $(1486.6 \mathrm{eV})$ was used at $15 \mathrm{~mA}$ emissions current and $15 \mathrm{kV}$ anode potential. Binding energy correction due to possible sample charging was applied by assuming the $\mathrm{C}_{1 s}$ core level line at $284.5 \mathrm{eV}$. Spectra were recorded at $40^{\circ}$ take-off angle relative to sample surface. Fibres were mounted to a sample stub using double sided copper tape. For data analysis, Wavemetrics IgorPro v.6.36 (WaveMetrics, Portland, USA) was used. Core level peaks were fitted using Voigt functions [23]; linear baseline was applied to the spectra. Energy-dispersive X-ray Spectroscopy (EDS) data were acquired using EDAX system annexed to a Zeiss Supra40 scanning electron microscope, at $10 \mathrm{kV}$ accelerating voltage. $10 \mu \mathrm{m} \times 10 \mu \mathrm{m}$ areas on the fibres were probed. Fibres were mounted to a sample stub using double sided copper tape. For data analysis, Oxford Instruments AZtecEnergy (Abingdon, UK) was used.

Both the fibre and composite fracture morphologies were investigated by scanning electron microscopy (SEM) using a Philips XL40 (Amsterdam, The Netherlands) and a FESEM Zeiss Auriga (Oberkochen, Germany). All specimens were sputter coated with gold prior to examination. Finally, fibre length distribution was measured for composites after injection moulding by dissolving the matrix in boiling $\left(120^{\circ} \mathrm{C}\right)$ tetrachloroethylene [24]. The fibres obtained were suspended in acetone and placed on a glass plate. The length of the fibres was determined by using optical microscopy (Nikon Eclipse 150L, Nikon, Tokyo, Japan) and at least 300 fibre lengths were recorded for each sample to characterise the distribution.

\subsection{Mechanical characterisation of composites}

Type 1BA samples $\left(l_{0}=30 \mathrm{~mm}\right)$ in accordance with UNI EN ISO 527-2 were used for tensile tests, which were carried out in displacement control using a crosshead speed of $10 \mathrm{~mm} / \mathrm{min}$ on a Zwick/Roell Z010 (Zwick/Roell GmbH, Ulm, Germany). The strain was measured with a contacting extensometer (Zwick/Roell GmbH, Ulm, Germany). The results reported in the work are the average of at least five tests for each material formulation.

\subsection{Thermal characterisation of composites}

The thermal behaviour of neat polymer and composites was investigated by differential scanning calorimetry (DSC) on three samples for each material type. Specimens were analysed in a Pyris I (Perkin Elmer, Waltham, USA) according to the following thermal program: heating from $-25^{\circ} \mathrm{C}$ to $180^{\circ} \mathrm{C}$ (5 min hold), cooling to $-25^{\circ} \mathrm{C}$ and heating to $180^{\circ} \mathrm{C}$, all steps at $10^{\circ} \mathrm{C} / \mathrm{min}$. This cooling and heating test method was adopted to ensure complete melting of the crystalline fraction of HDPE and to remove thermal history. The measurements were performed in nitrogen flow. The degree of crystallinity $\left(X_{c}\right)$ of the samples was calculated according to Eq. (3): 
Table 2

XPS and EDS data for Bas-PP and Bas-EP fibres.

\begin{tabular}{|c|c|c|c|c|}
\hline & \multicolumn{4}{|c|}{ Atom conc. } \\
\hline & \multicolumn{2}{|l|}{ Bas-PP } & \multicolumn{2}{|l|}{ Bas-EP } \\
\hline & XPS & EDS & XPS & EDS \\
\hline $\mathrm{C}$ & $83.9 \%$ & $26.8 \%$ & $82.3 \%$ & $32.6 \%$ \\
\hline $\mathrm{O}$ & $12.4 \%$ & $54.7 \%$ & $11.0 \%$ & $52.6 \%$ \\
\hline $\mathrm{Si}$ & $3.5 \%$ & $8.3 \%$ & $6.0 \%$ & $5.4 \%$ \\
\hline $\mathrm{N}$ & $0.3 \%$ & - & $0.7 \%$ & $1.1 \%$ \\
\hline $\mathrm{Mg}$ & - & $1.2 \%$ & - & $0.9 \%$ \\
\hline $\mathrm{Al}$ & - & $3.7 \%$ & - & $2.6 \%$ \\
\hline $\mathrm{Na}$ & - & $1.2 \%$ & - & $1.0 \%$ \\
\hline $\mathrm{Fe}$ & - & $4.1 \%$ & - & $3.8 \%$ \\
\hline
\end{tabular}

$X_{c}(\%)=\frac{\Delta H_{m}}{\Delta H_{m}^{0}\left(1-w_{f}\right)} \cdot 100$

where $\Delta H_{m}$ represents the experimental enthalpy of melting of the sample $(\mathrm{J} / \mathrm{g}), \Delta H_{m}{ }^{o}$ the enthalpy of melting for $100 \%$ crystalline HDPE $(\mathrm{J} / \mathrm{g})$, taken as $293 \mathrm{~J} / \mathrm{g}$ [25] and $w_{f}$ is the weight fraction of fibres.

Vicat softening temperature was determined according to ISO 306 following the test method $\mathrm{A} 120\left(10 \mathrm{~N}-120^{\circ} \mathrm{C} / \mathrm{h}\right)$ using a CEAST/Intron HV6A (Instron, Massachusetts, USA).

\section{Results and discussion}

\subsection{Fibre/matrix adhesion of different basalt fibres in HDPE matrix}

XPS and EDS results for Bas-PP and Bas-EP fibres are shown and summarised in Table 2 and Fig. 2. Composition probed by XPS appears very similar for both sizings. $\mathrm{C}_{1 s}, \mathrm{O}_{1 s}, \mathrm{Si}_{2 p}$ and $\mathrm{N}_{1 s}$ core lines are detected. Carbon and oxygen represent the preponderance of surface composition. A slightly difference in the silicon and nitrogen content can be noticed between Bas-PP and Bas-EP, (the latter having more silicon and nitrogen). As pointed out in [26], in a similar case (analysis of glass fibre surface and sizing), an XPS measurement was able to detect both atoms characteristic of the sizing (i.e. carbon, oxygen and nitrogen, but also silicon, if a silane is used in sizing formulation), as well as atoms characteristic of the fibre (in our case, silicon, oxygen, aluminum, alkali metals and alkaline earth metals), if the sizing is thin (thickness comparable with photoelectron escape depth, i.e. some

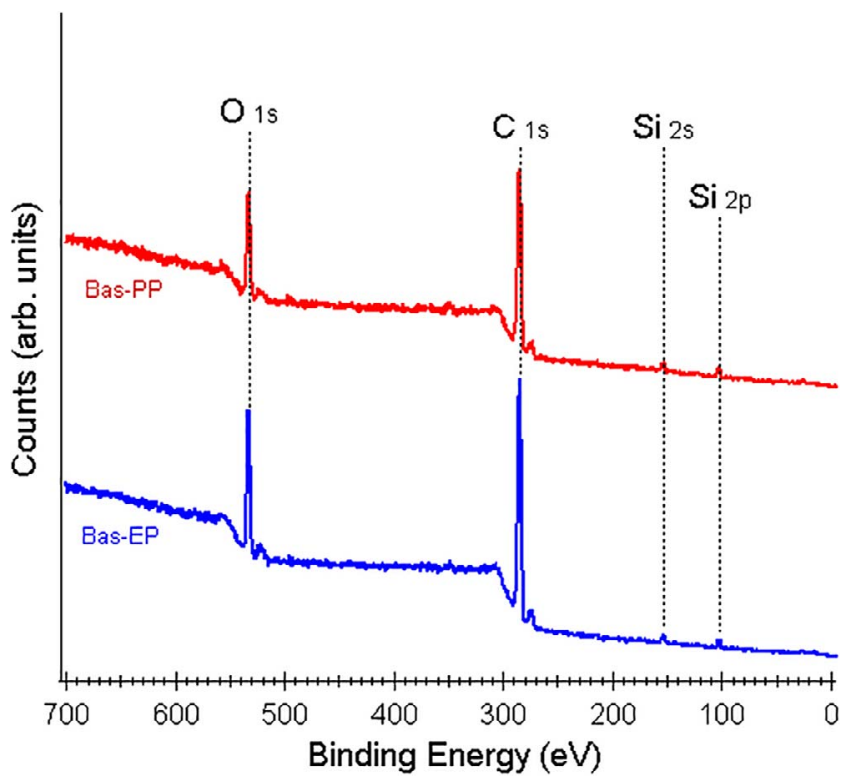

Fig. 2. XPS survey spectra of Bas-PP and Bas-EP fibres (arb. means arbitrary).
Table 3

Critical fragment length $\left(L_{f c}\right)$, critical fibre aspect ratio $\left(L_{c} / d\right)$, apparent IFSS values and amount of investigated fragments $(n)$ from SFFT.

\begin{tabular}{lllll}
\hline Basalt fibre & $\mathrm{L}_{\mathrm{fc}}(\mathrm{mm})$ & $\mathrm{L}_{\mathrm{c}} / \mathrm{d}$ & IFSS (MPa) & $\mathrm{n}$ \\
\hline Bas-EP & $6.23 \pm 2.62$ & 47.9 & $2.10 \pm 0.99$ & 17 \\
Bas-PP & $3.02 \pm 0.94$ & 23.2 & $6.12 \pm 4.88$ & 39 \\
\hline
\end{tabular}

nanometers) and/or not uniform. In our measurements, carbon detected stems from sizing but also likely from atmospheric adventitious carbon contamination. Basalt fibre typical elements (with the exception of silicon and oxygen) are not detectable, pointing out that sizing is covering uniformly the fibre's surface, with a thickness higher than photoelectrons escape depth. On the other hand, EDS (probing depth: some microns) is able to detect underlying basalt elements ( $\mathrm{Al}, \mathrm{Mg}, \mathrm{Na}$ and Fe), and a smaller amount of carbon (compared to XPS) Considering this probing volume, Bas-EP coating appears thicker than BasPP (ratio between C and basalt elements is higher in Bas-EP).

Both types of basalt fibres exhibited similar tensile strengths, irrespective of the different fibre sizing. An average value of $1447 \mathrm{MPa}$ was found for both fibres, the difference being mainly related to the dispersion of data (standard deviation) that was higher for Bas-PP compared to Bas-EP, namely $727 \mathrm{MPa}$ compared to $592 \mathrm{MPa}$. These tensile strength results, which are comparable with those reported by Greco et al. [19], were used for calculating the apparent IFSS whose values are summarised in Table 3. Basalt fibres with epoxy-compatible sizing exhibited a very poor adhesion with HDPE matrix, which was three times higher for basalt Bas-PP fibres. At the same time, a clearly higher critical fragment length, which is equal to the critical fibre length, and critical fibre aspect ratio is determined for Bas-EP (compare Table 2). This means that Bas-EP fibres need to be more than twice as long as Bas-PP fibres to lead to a reinforcing effect in a HDPE composite. In both cases the IFSS values appear to be low. The frictional debonding as shown in Fig. 1 is also an indicator for weak fibre/ matrix adhesion [27]. But the IFSS data are comparable with data available in literature for other systems: unsized carbon fibres in an epoxy system (by SFFT) [28], basalt fibres in non-modified polypropylene matrix (by SFFT) [19], glass fibres in polypropylene matrix (by SFFT) [29]. The IFSS was found to be higher than that of natural fibres in some polyolefin matrices, such as sisal in polyethylene matrix (by SFFT) [30], henequen in polyethylene matrix (by fibre pull-out and SFFT) [31], jute and bamboo fibres in polypropylene matrix (by SFFT) [32]. Despite similarities in sizing, the two basalt fibres exhibited significantly different adhesion with the polyethylene matrix, therefore Bas-PP fibres were chosen as reinforcement in the present study. It is also clear the need to improve the level of interfacial adhesion through the use of a suitable coupling agent. In this regard, the use of maleated coupling agents for glass reinforced composites is well known and widely practiced, therefore it was decided to apply the same strategy also in basalt fibre reinforced composites, taking into account also some recent positive applications [33].

\subsection{Fibre aspect ratio}

Fibre aspect ratio was investigated because the higher the aspect ratio $(l / d)$ the higher the contact surface area between fibre and matrix, which results in a better load transfer efficiency. During processing, namely extrusion compounding followed by injection moulding, fibres are subjected to strong shear stresses and friction phenomena that reduce their length and their aspect ratio as well. One of the main factors affecting fibre breakage is fibre-fibre interaction [34]. Fig. 3 depicts the effect of increasing fibre content on fibre aspect ratio of basalt and hemp fibre composites. Basalt fibres exhibited an initial aspect ratio of 246.15 that, after processing, reduced to around 21 for a composite reinforced with $40 \mathrm{wt} \%$ of basalt fibres. The critical aspect ratio for 


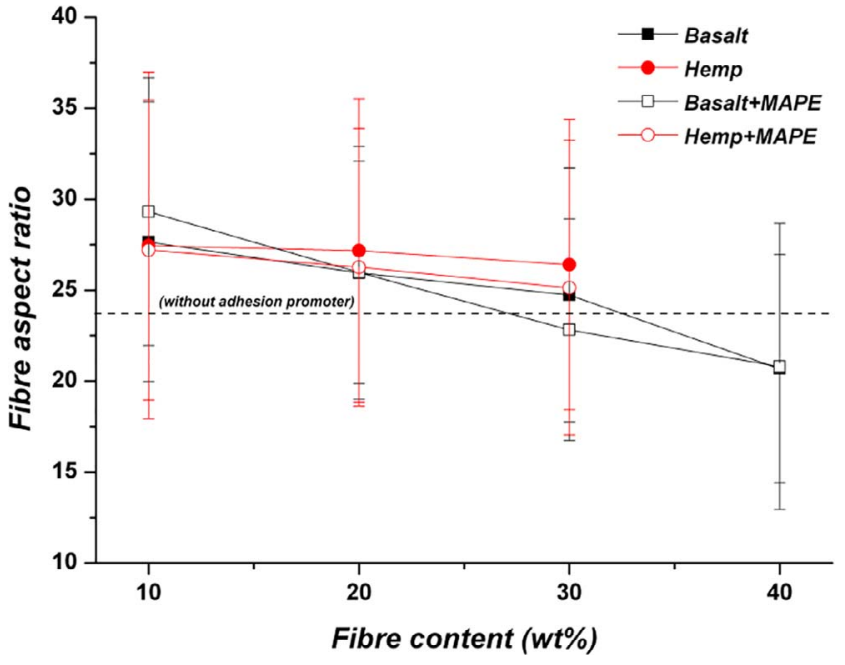

Fig. 3. Fibre aspect ratio as a function of fibre content for basalt and hemp fibre reinforced composites. The dotted line shows the critical aspect ratio $\left(\mathrm{L}_{\mathrm{c}} / \mathrm{d}\right)$ for basalt fibres in HDPE without adhesion promoter.

basalt/HDPE without adhesion promoter was determined to be 23 (compare Table 3). A lower critical aspect ratio is assumed for composites with adhesion promoter. For basalt/HDPE (without adhesion promoter) it can be noted that the mean aspect ratio is clearly higher than the critical aspect ratio up to a fibre mass fraction of $30 \%$. At a fibre mass fraction of $40 \%$ the aspect ratio decreased below the critical aspect ratio. For hemp fibres the initial aspect ratio was 37.78 and the final one was about 26 . The initial aspect ratio for hemp fibres is significantly lower than basalt one because these fibres were previously extruded and pelletised in order to produce the commercial compound. From Fig. 3 it can be observed that both fibres exhibited a significant decrease in aspect ratio with increasing fibre content due to a significant increase in shear stresses and fibre-fibre interactions, but hemp fibres appeared to be less prone to fibre aspect ratio reduction compared to basalt fibres. This behaviour can be ascribed to the lower bending stiffness of hemp fibres and to fibrillation phenomena that usually result in a marked reduction in natural fibre diameters [35-37]. The presence of coupling agent did not seem to play a significant role, as similar aspect ratio reductions were detected for hemp and basalt fibre reinforced composites. But the adhesion promoter leads to lower critical aspect ratio [21], and therefore to a better reinforcement effect of the fibres. Fig. 4 shows the aspect ratio distributions for basalt and

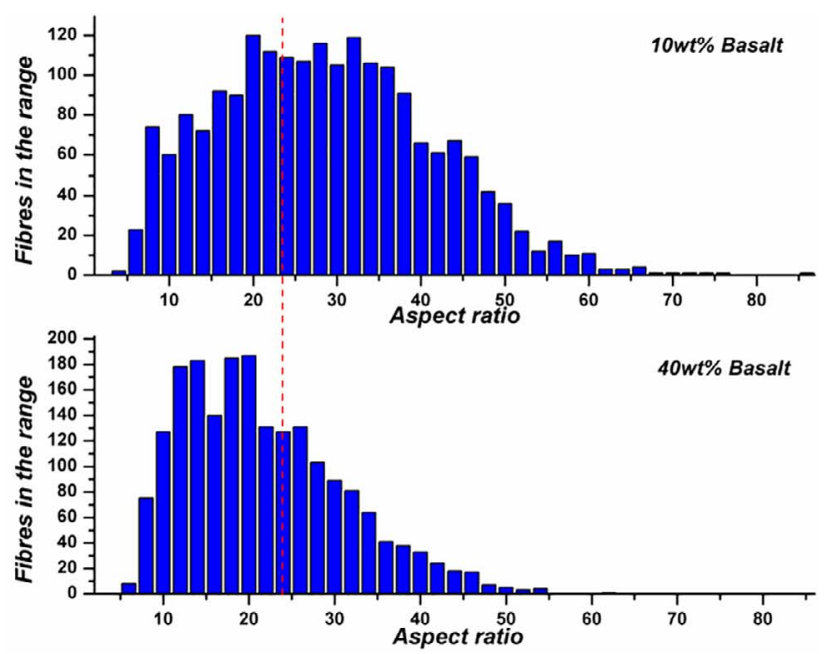

hemp fibre composites in order to depict their evolution with fibre content. At the lower fibre content, aspect ratios have wide and unsymmetric distributions, which tend to become narrower and shifted toward the left side, thus confirming a decrease in fibre aspect ratio at higher fibre mass fractions [38]. In hybrid composites, when the weight fraction ratio of the two types of fibres is varied, the interaction between these fibres leads to changes in fibre length [39]. In this study, a similar procedure performed on composites with coupling agent and $15 \mathrm{wt} \%$ of basalt $+15 \mathrm{wt} \%$ of hemp fibres, pointed out that aspect ratios were equal to $25.22 \pm 9.86$ and $26.04 \pm 8.56$ for basalt and hemp fibres, respectively. In addition, average fibre length of basalt fibres was found to be $327.80 \pm 99.02 \mu \mathrm{m}$, while hemp fibres in hybrids exhibited an average fibre length of $558.61 \pm 102.78 \mu \mathrm{m}$. The value for basalt fibres in the hybrid composite is slightly higher than the one for composites with only basalt fibres at $30 \mathrm{wt} \%$ $(296.74 \pm 89.46 \mu \mathrm{m})$, while the average length of hemp fibres in hybrids was higher than that of pure hemp composites at $30 \mathrm{wt} \%$ $(406.29 \pm 114.49 \mu \mathrm{m})$. This indicates that basalt-hemp fibre interaction brings about less damage to the respective fibres than the basalt-basalt and hemp-hemp interactions. It is also worth mentioning that most of the basalt fibres have a length less than hemp fibres and likely lower than the respective critical fibre length, which may lead to basalt fibre pull out instead of fibre fracture during tensile loading of the composites.

\subsection{Tensile properties of composites}

Tensile stress-strain curves of some representative composites, namely neat HDPE, HDPE/hemp, HDPE/basalt and hybrid HDPE/basalt/hemp are shown in Fig. 5. Neat HDPE exhibited a ductile behaviour while all composites showed a much more macroscopic brittle fracture with a linear deformation at lower strains followed by a non linear deformation with increasing strain up to final failure. As a general comment, the incorporation of both basalt and hemp fibres increased the tensile modulus and strength of neat HDPE with better results offered by basalt fibres due to their higher strength and stiffness compared to hemp fibres. The strain at failure was found to decrease with increasing fibre content, especially for basalt fibre composites, which can be ascribed to the more brittle nature of basalt fibres compared to hemp ones. In order to better discriminate the reinforcement efficiency between basalt and hemp fibres, the variation of tensile properties as a function of basalt and hemp fibre content is reported in Fig. 6. From Fig. 6 it can be inferred that basalt reinforced composites exhibited better mechanical properties than hemp fibre composites, due to the

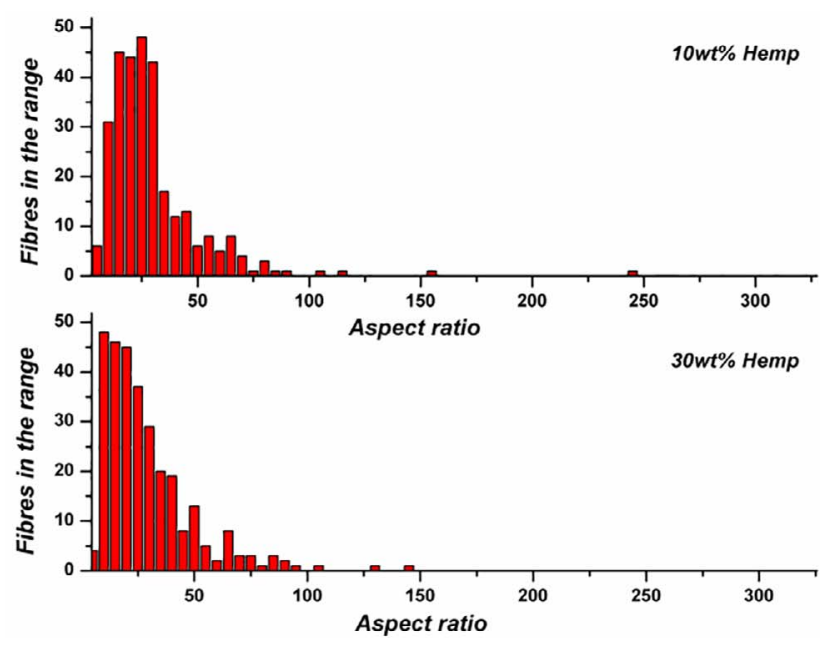

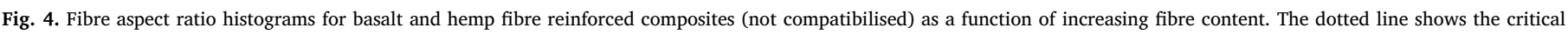
aspect ratio $\left(\mathrm{L}_{\mathrm{c}} / \mathrm{d}\right)$ for basalt fibres in HDPE without adhesion promoter. 


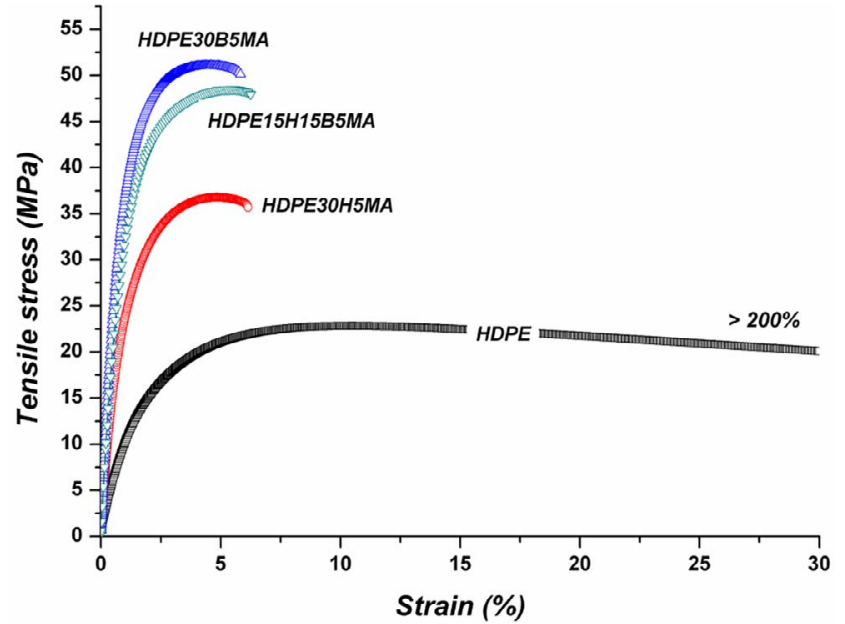

Fig. 5. Tensile stress-strain curves of neat HDPE, HDPE/basalt, HDPE/hemp and hybrid HDPE/basalt/hemp composites.

higher intrinsic mechanical properties of basalt fibres. Modulus for basalt fibre composites increased with increasing basalt content irrespective of the presence of the coupling agent, while tensile strength increased significantly only up to $30 \mathrm{wt} \%$ in non-compatilised system, thus confirming that at $40 \mathrm{wt} \%$ most of the basalt fibres were characterised by an aspect ratio below the critical one. This behaviour was instead balanced by the increase in fibre/matrix adhesion in the compatibilised system. It is also worth mentioning that incorporation of hemp fibres increased not only the Young's modulus, which is a quite common finding in literature $[35,40]$, but also the tensile strength even in the untreated condition for injection-moulded composites compared to the neat matrix. This can be ascribed to a combination of a reduced decrease in fibre aspect ratio with increasing fibre content, due to fibrillation phenomena, and the increased degree of crystallinity of HDPE due to the nucleating effect of hemp fibres, as will be confirmed by DSC analysis. In particular, the separation of fibre bundles into their single fibres would result in a significant increase in the interphase area between fibres and matrix.

As regards the effect of coupling agent, it is worth noting that the coupling agent does not seem to affect the properties of the neat HDPE. The Young's modulus and the tensile strength, were improved by both basalt and hemp fibres. It is also interesting to note that coupling agent allowed the attainment of a much more sustained uniform ductility in the specimens. This behaviour can be ascribed to the easier dispersion of the fibres in the compounding and injection processes and the resultant avoidance of fibre agglomeration which is responsible for stress intensification causing early fracture of composites [41]. It is clear for basalt fibres that only the presence of the sizing is not enough to provide a sound interfacial adhesion, as confirmed by the results of the single fibre fragmentation test. The covalent bonding between the anhydride group with the hydroxyl groups of hemp and basalt fibres, in combination with chain entanglement between MAPE and HDPE chains, create a good stress transfer interphase [42]. This is supported and confirmed by SEM observations of the fracture surfaces of tensile tested composites, as shown in Figs. 7 and 8 for basalt and hemp fibre reinforced composites, respectively. It is possible to observe the higher level of adhesion due to the addition of the coupling agent. For untreated composites, fibre pull-out as well as gaps between fibre and matrix were detected irrespective of fibre type and the fractured surfaces revealed extensive fibre/matrix debonding with fibres only hardly wetted by the matrix. In particular, basalt fibres exhibited a large degree of pull-outs compared to hemp fibres, which can be attributed to the fact that most basalt fibres have a smaller aspect ratio and higher tensile strength compared to hemp fibres. As shown in Fig. 4 and Table 3 many basalt fibres display aspect ratios below the critical aspect ratio. On the contrary, composites with coupling agent showed fibres uniformly coated with the matrix and reduced pull-out lengths, which suggest enhanced interfacial adhesion as confirmed by the mechanical properties (compare Fig. 6).
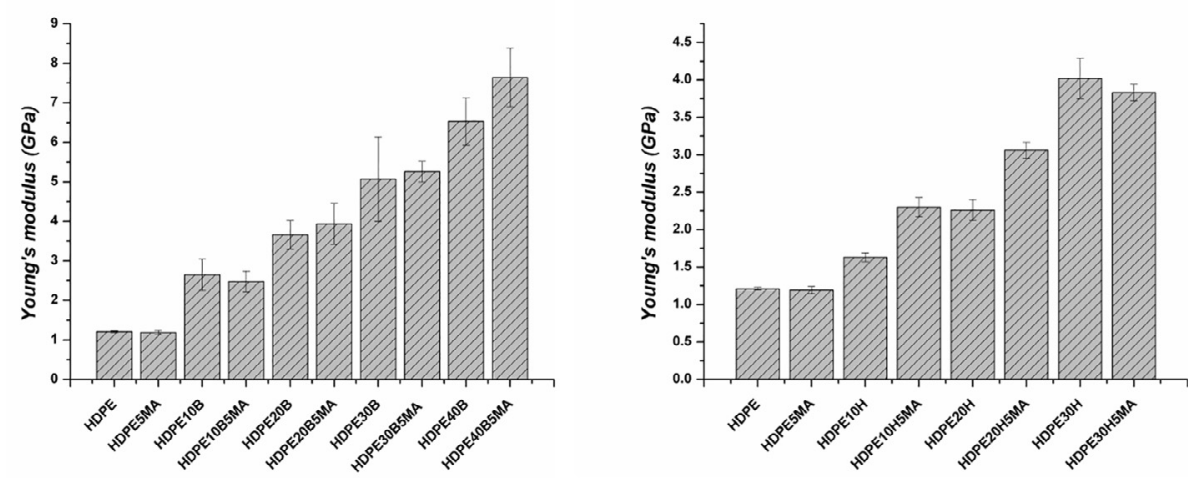

Fig. 6. Effect of basalt and hemp fibre amount on tensile strength and modulus of their resulting HDPE composites.
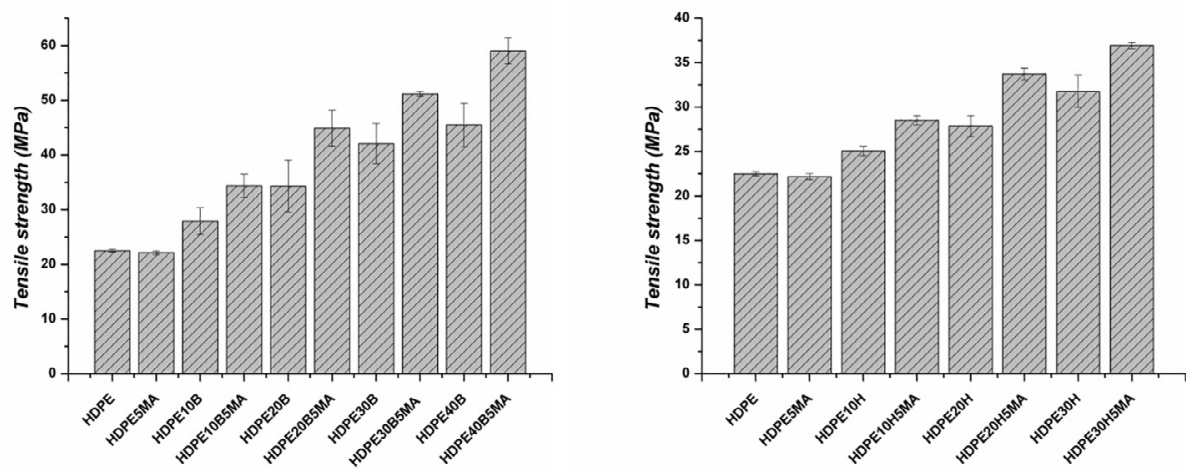


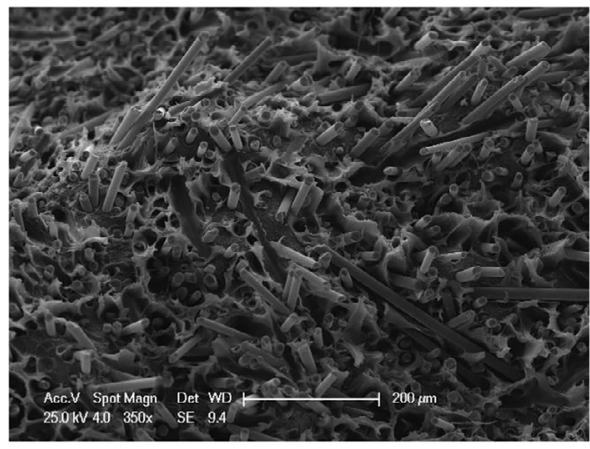

(a)

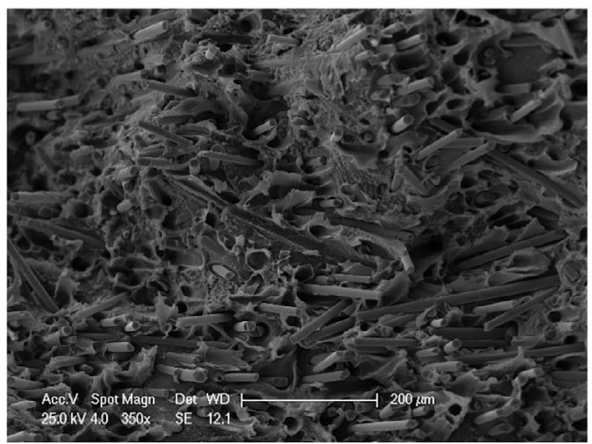

(c)

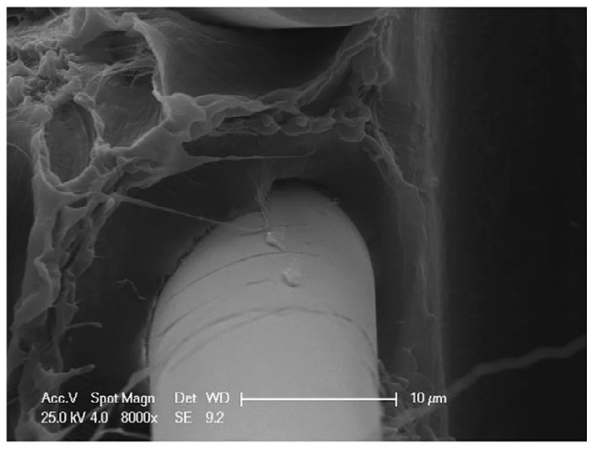

(b)

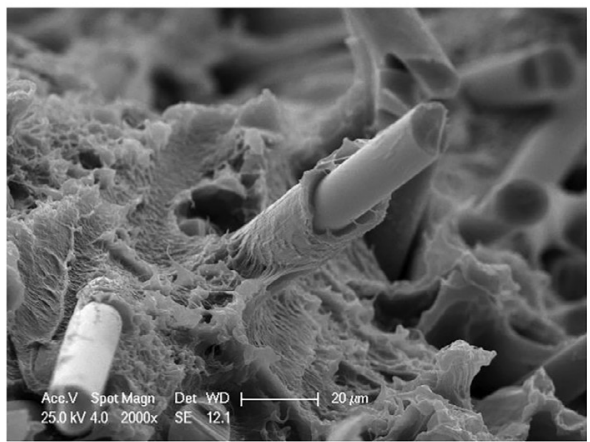

(d)
Fig. 7. SEM micrographs of tensile fracture surfaces of basalt/HDPE composites under different magnifications without (a-b) and (c-d) with coupling agent.
Variation of mechanical properties with increasing basalt fibre content in hemp/basalt fibre hybrid composites is shown in Fig. 9. The total fibre amount of the hybrid composites was maintained at $30 \mathrm{wt} \%$ and, for comparison purposes, the mechanical properties of composites reinforced with only $30 \mathrm{wt} \%$ of basalt and hemp fibres are included. The results are reported only for compatibilised systems, due to their better mechanical properties. Improvements in strength and modulus of hemp fibre reinforced composites were detected with the addition of

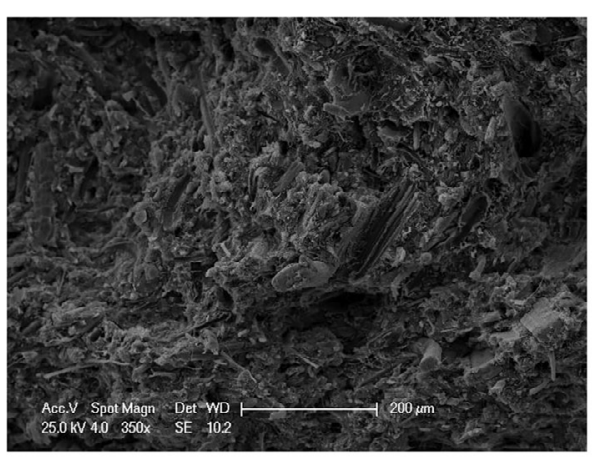

(a)

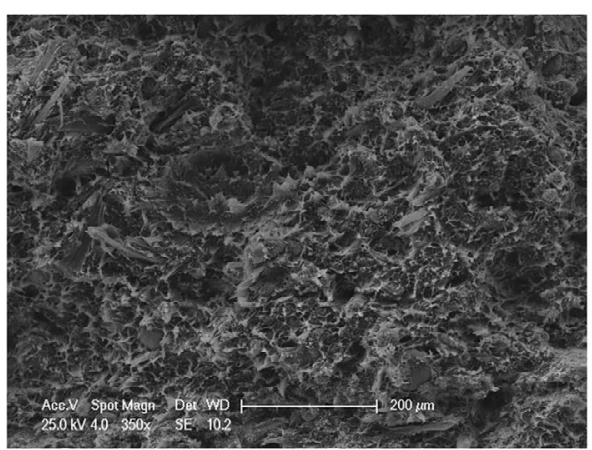

(c)

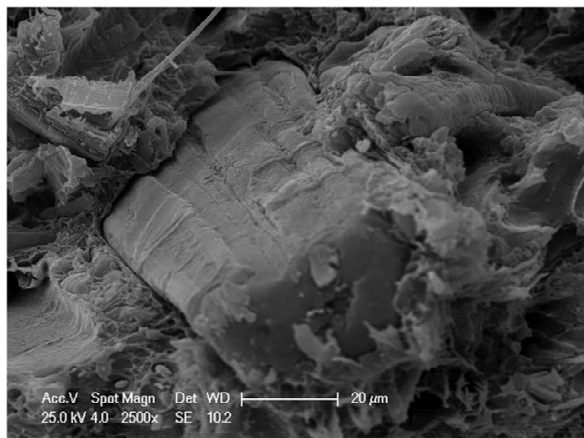

(b)

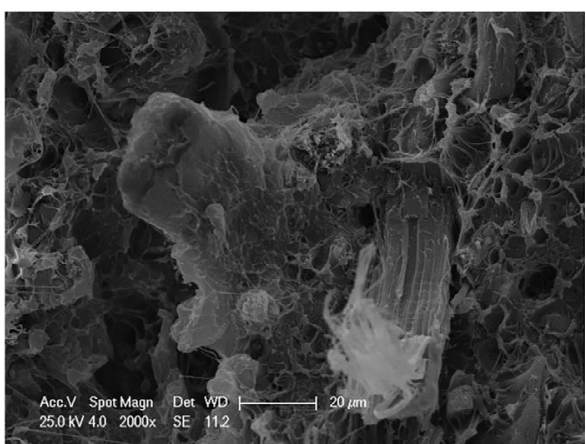

(d)
Fig. 8. SEM micrographs of tensile fracture surfaces of hemp/HDPE composites under different magnifications without (a-b) and (c-d) with coupling agent. 

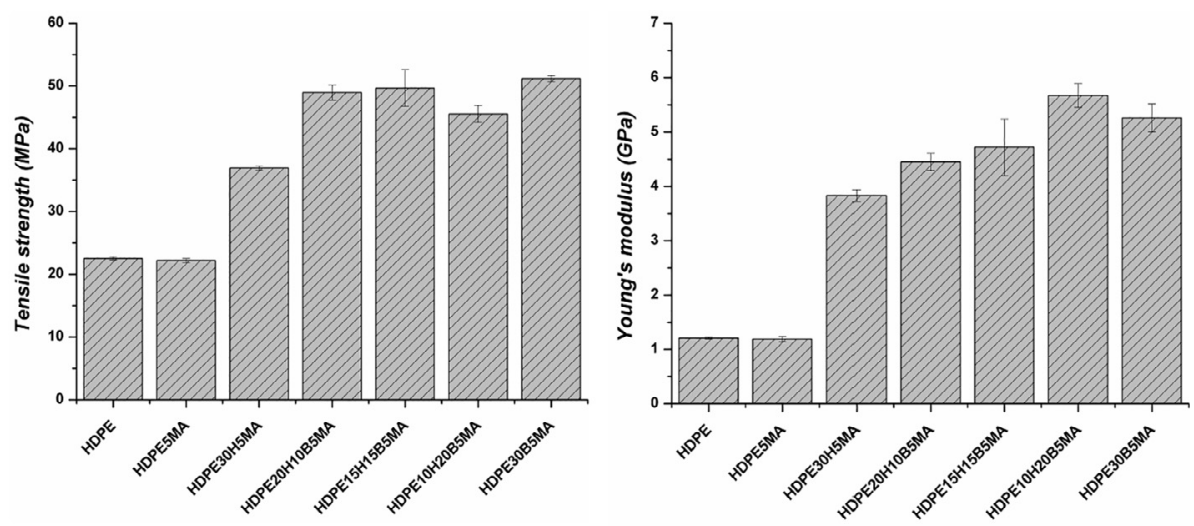

Fig. 9. Effect of basalt fibre content on tensile strength and modulus of hemp/basalt hybrid HDPE composites. basalt fibres due to the better mechanical properties of basalt fibres, as confirmed by other studies based on the incorporation of glass fibres in natural fibre composites [8]. It is also worth noting that hybrid composites exhibited mechanical properties similar to the ones found for composites reinforced only with basalt fibres with the same amount of fibres, likely ascribed to the less damage experienced by the respective fibres during the processing steps, but in any case lower compared to the properties of compatibilised basalt fibre reinforced composites at $40 \mathrm{wt} \%$, which instead exhibited the highest strength and stiffness despite the reduced aspect ratio. From the results, some peculiar behaviours were observed, in particular the slightly higher strength of composites with equal ratio of hemp and basalt fibres compared to hybrids with higher percentage of basalt fibres. This may be ascribed to longer basalt fibres as a result of synergistic interactions during compounding, while higher degree of alignment of longer basalt fibres during injection moulding could be responsible for slightly increased modulus compared to a $30 \mathrm{wt} \%$ basalt fibre composite. However these hypotheses related to the complex interactions of basalt and hemp fibres deserve a deeper investigation.

\subsection{Thermal properties of composites}

The thermal properties of neat HDPE and resulting composites with and without coupling agent were investigated by DSC and the thermograms were found to be conventional and very similar to each other and therefore were not included in the present paper, while the melting and crystallisation parameters obtained from DSC curves are summarised in Table 4. In particular, the values of melting temperature $\left(T_{m}\right)$ and associated enthalpy $\left(\Delta H_{m}\right)$ were calculated from the second heating scan, while the crystallisation temperature $\left(T_{c}\right)$ was calculated from the cooling curve. For neat matrices, a slight decrease in the total degree of crystallinity was detected due to the addition of coupling agent which could result in a decrease of the regularity of the matrix molecular chains and related packing efficiency. The presence of both fibres caused a reduction of melting temperature compared to the neat matrix thus suggesting a decrease in perfection of matrix crystallites due to heterogeneous nucleation promoted by the presence of the fibres [43]. This is confirmed by the general increase of the degree of crystallinity regardless of fibre type. Even if it is not possible to obtain the exact fibre amount in order to calculate the precise degree of crystallinity from DSC measurements due to the small sample size, the nucleating effect of basalt and hemp fibres is evident from the overall increase in the degree of crystallinity compared to the neat matrix and from the slightly higher crystallisation temperature for the filled systems. This is a clear effect of the transcrystalline phenomena which enable the HDPE chains to crystallise at higher temperatures, therefore more easily. The higher crystallinity is one more aspect to explain the improved mechanical properties of untreated hemp fibre composites over neat HDPE. The presence of the coupling agent appears to reduce the overall degree of crystallinity, as observed in other studies $[40,44]$, possibly due to a lower fibre surface area available for the transcrystallinity effect. The higher ductility of compatibilised systems is likely due to the lower degree of crystallinity as amorphous domains are in the rubbery state at room temperature thus being much more prone to undergo strain. As regards hybrid composites, the crystallinity of hemp/fibre composites was found to increase with increasing basalt content, and the adverse effect of coupling agent was confirmed also in this case. The overall degree of crystallinity of hybrid composites appears to be somewhat lower compared to composites with single fibres, which is likely to be ascribed to complex interactions between basalt and hemp fibres. It is known that depending on the filler

Table 4

Thermal properties of selected composites obtained from DSC analysis.

\begin{tabular}{|c|c|c|c|c|}
\hline Sample & $\mathrm{T}_{\mathrm{c}}\left({ }^{\circ} \mathrm{C}\right)$ & $\mathrm{T}_{\mathrm{m}}\left({ }^{\circ} \mathrm{C}\right)$ & $\Delta \mathrm{H}_{\mathrm{m}}(\mathrm{J} / \mathrm{g})$ & $\mathrm{X}_{\mathrm{c}}(\%)$ \\
\hline HDPE & $121.30 \pm 0.78$ & $146.22 \pm 0.90$ & $187.99 \pm 23.64$ & $64.16 \pm 3.58$ \\
\hline HDPE5MA & $121.58 \pm 0.42$ & $143.74 \pm 1.78$ & $186.09 \pm 13.29$ & $63.51 \pm 4.53$ \\
\hline HDPE10B & $121.31 \pm 1.08$ & $143.65 \pm 1.92$ & $187.54 \pm 12.09$ & $71.12 \pm 4.58$ \\
\hline HDPE30B & $121.73 \pm 0.44$ & $142.98 \pm 1.19$ & $148.91 \pm 7.72$ & $72.6 \pm 3.77$ \\
\hline HDPE10B5MA & $122.02 \pm 1.06$ & $143.73 \pm 1.09$ & $177.36 \pm 6.07$ & $67.26 \pm 2.30$ \\
\hline HDPE30B5MA & $121.72 \pm 0.12$ & $143.65 \pm 0.22$ & $146.99 \pm 7.61$ & $71.67 \pm 3.71$ \\
\hline HDPE10H & $122.25 \pm 0.55$ & $142.98 \pm 0.04$ & $194.62 \pm 6.99$ & $73.78 \pm 2.64$ \\
\hline HDPE30H & $121.69 \pm 0.27$ & $139.22 \pm 0.25$ & $165.94 \pm 13.81$ & $80.91 \pm 3.63$ \\
\hline HDPE10H5MA & $123.13 \pm 0.11$ & $140.95 \pm 0.06$ & $182.97 \pm 6.30$ & $69.38 \pm 2.39$ \\
\hline HDPE30H5MA & $122.83 \pm 0.43$ & $139.86 \pm 0.56$ & $144.09 \pm 6.30$ & $70.25 \pm 3.07$ \\
\hline HDPE10H20B & $122.60 \pm 0.28$ & $142.04 \pm 0.64$ & $164.74 \pm 15.84$ & $80.32 \pm 6.06$ \\
\hline HDPE15H15B & $122.49 \pm 0.11$ & $140.76 \pm 0.11$ & $130.40 \pm 10.70$ & $63.58 \pm 5.51$ \\
\hline HDPE20H10B & $123.13 \pm 0.33$ & $139.26 \pm 0.26$ & $110.58 \pm 12.76$ & $53.91 \pm 6.22$ \\
\hline HDPE10H20B5MA & $123.05 \pm 0.45$ & $141.62 \pm 1.43$ & $132.29 \pm 1.71$ & $64.50 \pm 0.83$ \\
\hline HDPE15H15B5MA & $122.59 \pm 0.26$ & $141.18 \pm 1.58$ & $129.69 \pm 1.28$ & $63.23 \pm 0.63$ \\
\hline HDPE20H10B5MA & $122.97 \pm 0.09$ & $139.93 \pm 1.66$ & $117.61 \pm 9.67$ & $57.34 \pm 4.72$ \\
\hline
\end{tabular}



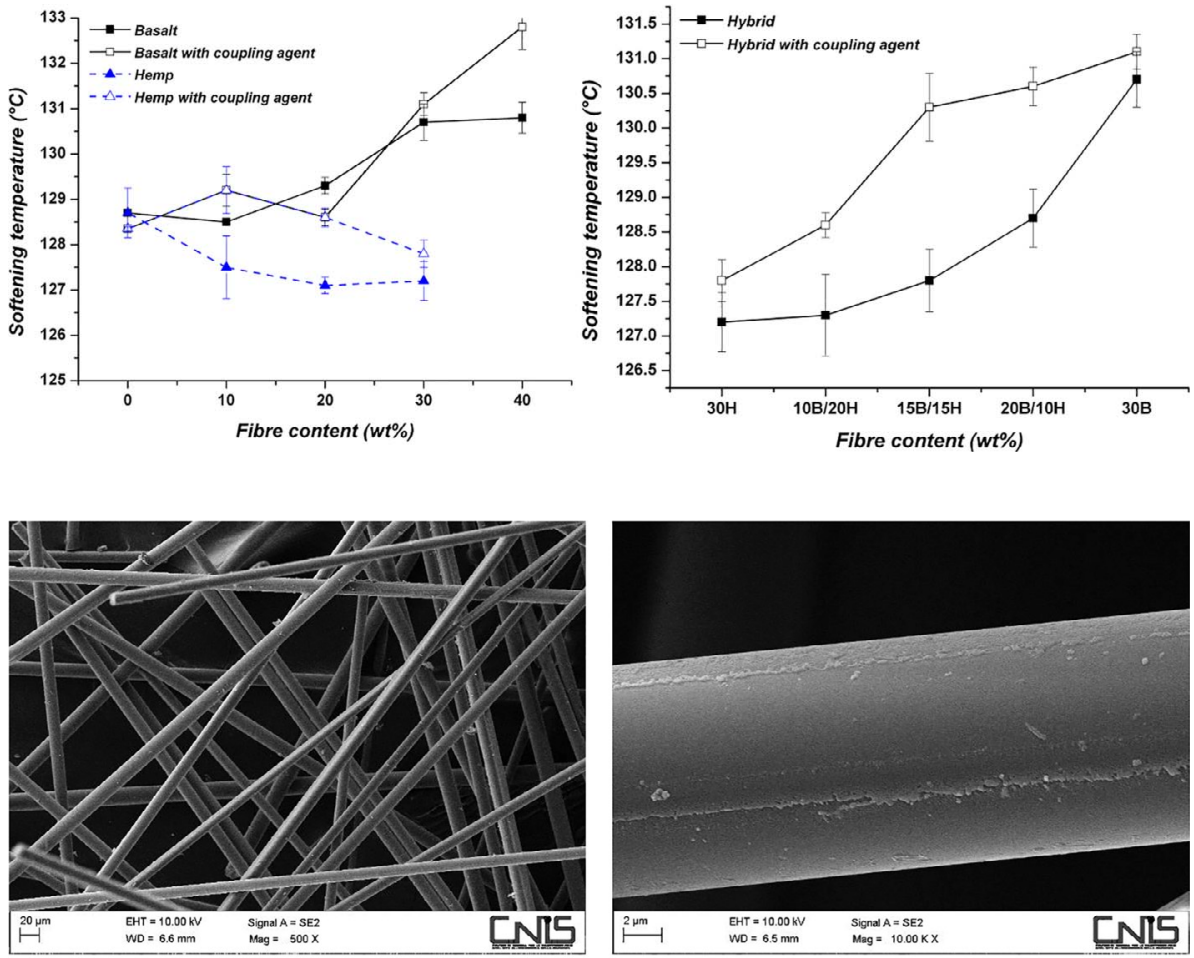

(a)

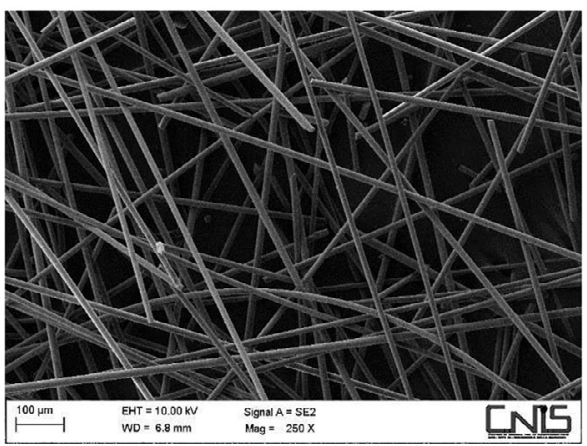

(c)

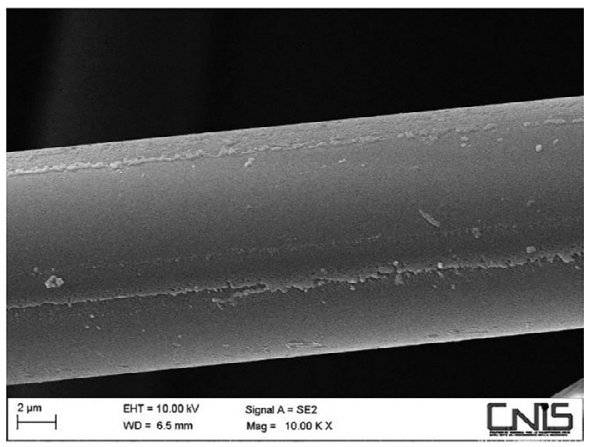

11. SEM micrographs of basalt fibres treated in acetone (a-b) and (c-d) in acetone followed by thermal treatment (TT)
Fig. 10. Vicat softening temperature as a function of fibre type and content for composites based on HDPE. (b)

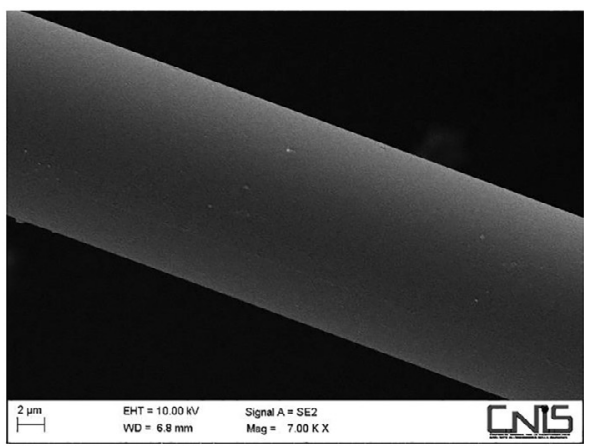

(d)
Table 5

XPS and EDS data for Bas-PP: non treated and treated fibres (acetone and acetone + thermal treatment).

\begin{tabular}{|c|c|c|c|c|c|c|}
\hline & \multicolumn{6}{|c|}{ Atom conc. } \\
\hline & \multicolumn{2}{|l|}{ Bas-PP } & \multicolumn{2}{|c|}{ Bas-PP + acetone } & \multicolumn{2}{|c|}{ Bas-PP + acetone + thermal treatment } \\
\hline & XPS & EDS & XPS & EDS & XPS & EDS \\
\hline $\mathrm{C}$ & $83.9 \%$ & $26.8 \%$ & $76.8 \%$ & $15.4 \%$ & $68.2 \%$ & $2.8 \%$ \\
\hline $\mathrm{O}$ & $12.4 \%$ & $54.7 \%$ & $14.5 \%$ & $61.7 \%$ & $19.3 \%$ & $65.9 \%$ \\
\hline $\mathrm{Si}$ & $3.5 \%$ & $8.3 \%$ & $7.9 \%$ & $10.6 \%$ & $10.1 \%$ & $16.5 \%$ \\
\hline $\mathrm{N}$ & $0.3 \%$ & - & - & - & - & - \\
\hline $\mathrm{Mg}$ & - & $1.2 \%$ & - & $1.6 \%$ & - & $2.0 \%$ \\
\hline $\mathrm{Al}$ & - & $3.7 \%$ & $0.8 \%$ & $4.6 \%$ & $2.4 \%$ & $6.2 \%$ \\
\hline $\mathrm{Na}$ & - & $1.2 \%$ & - & $1.4 \%$ & - & $2.0 \%$ \\
\hline $\mathrm{Fe}$ & - & $4.1 \%$ & - & $4.7 \%$ & - & $4.6 \%$ \\
\hline
\end{tabular}

content, nature and dispersion, transcrystallisation phenomena can be affected by fibre-fibre contacts and agglomeration and therefore the values of crystallinity and melting temperature can increase or decrease depending on the nucleating ability of the fillers [45-47].
Vicat softening temperature is a parameter usually adopted to establish the service temperature of thermoplastic polymers and can be interpreted as a temperature at which the modulus has reached a particular level, being related to the fundamental properties of the material [48]. Fig. 10 shows Vicat temperature as a function of filler type and content for HDPE-based composites. As shown, the Vicat temperature was found to increase with the basalt content and the effect is more evident in compatibilised systems, due to increased modulus and fibre/ matrix interaction $[17,49]$. The introduction of hemp fibres did not improve the softening temperature likely due to a contemporaneous softening with temperature of hemp fibres. In this case the presence of coupling agent is still not able to counteract the negative role played by fibre softening. Hybridisation with basalt fibres was beneficial to the heat resistance of hemp fibre composites.

\subsection{Effect of basalt sizing removal on mechanical properties of resulting} composites

The effects of sizing removal from basalt fibres can be seen from the SEM analysis of fibre surfaces reported in Fig. 11. The fibre surface of 


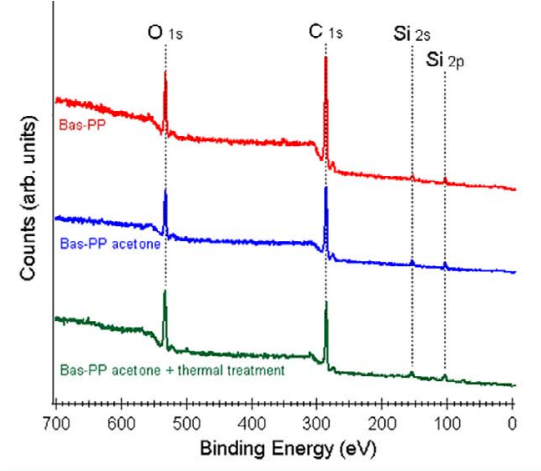

(a)

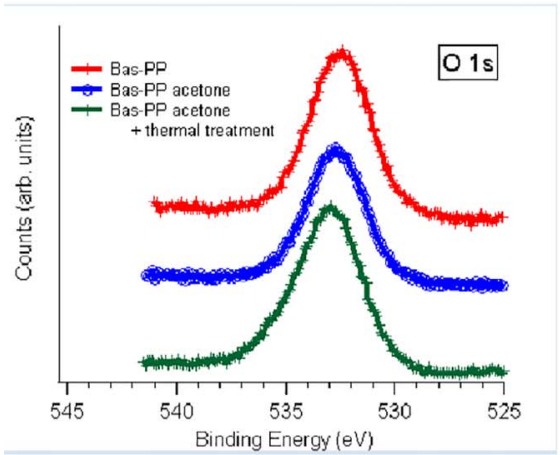

(c)

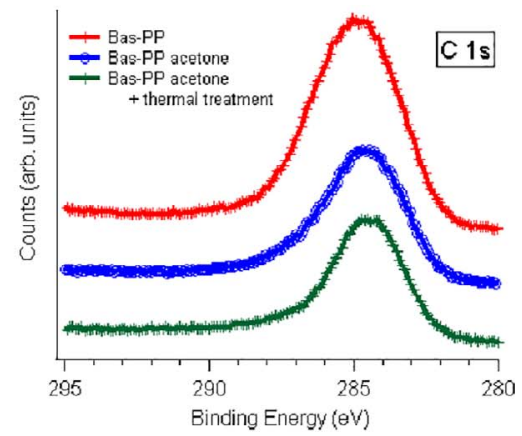

Fig. 12. (a) XPS survey spectra of Bas-PP fibres without any sizing removal treatment, after acetone sizing removal treatment and after acetone + thermal treatment (TT); (b-e) XPS $\mathrm{C}_{1 \mathrm{~s}}, \mathrm{O}_{1 \mathrm{~s}}, \mathrm{Si}_{2 \mathrm{p}}$ and $\mathrm{Al}_{2 \mathrm{p}}$ detail region of Bas-PP fibres subjected to different sizing removal treatments (arb. means arbitrary). (b)

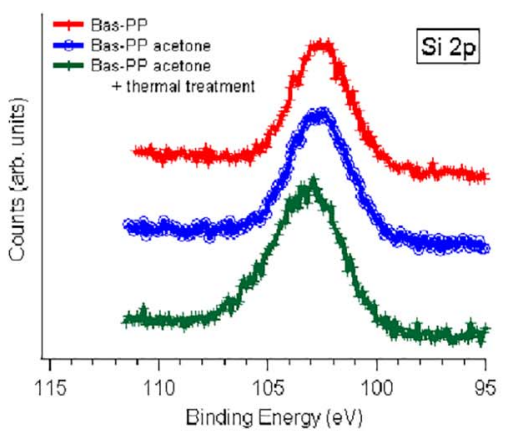

(d)

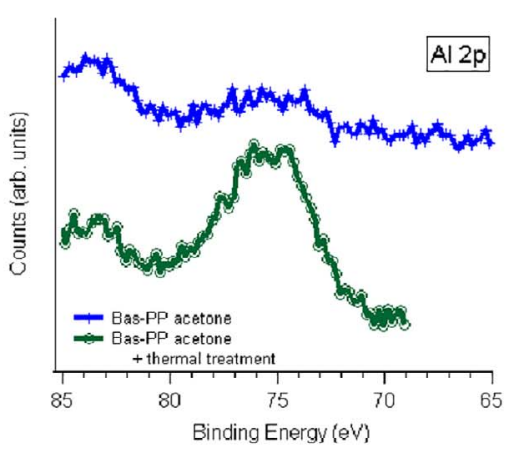

(e)

basalt fibres treated only with acetone still displays evident roughness due to sizing only partially removed, while a much more smooth surface was observed for fibres treated with a combination of acetone and thermal treatments (Fig. 11c and d). In order to effectively assess the removal of sizing, XPS and EDX measurements were performed on fibres subjected to both treatments and results are summarised in Table 5 and Fig. 12. Carbon content detected by XPS decreases after sizing removal procedure (from $84 \%$ to $77 \%$ with acetone; from $84 \%$ to $68 \%$ with acetone and thermal treatment). Oxygen and Silicon content rise (O: from $12 \%$ to $14.5 \%$ after acetone, and to $19 \%$ after thermal treatment; Si: from $3.5 \%$ to $8 \%$ after acetone, and up to $10 \%$ after thermal treatment) and a small amount of Aluminum (element ascribed to basalt) can be detected after the treatments. High residual carbon content after treatments (68\%) should not mislead to the conclusion that the sizing removal was not effective. Due the surface-sensitive nature of the technique, most of this carbon signal could be likely due to adventitious carbon contamination and not to the sizing. The increase in oxygen and silicon content, as well as detection of aluminum, point out that the underlying fibre is exposed to XPS probing, suggesting a thickness reduction and/or a lack of uniformity in the sizing. This is also supported by EDS data (probing a deeper volume), that clearly show a remarkable reduction in carbon content (from $26 \%$ of non treated sample to $15 \%$ of acetone-treated sample, and to $2 \%$ of thermal treated sample) and an increase of the typical basalt elements content.

Composites with 10 and $30 \mathrm{wt} \%$ of basalt fibres subjected to both sizing removal processes were manufactured and mechanically tested. This experimental investigation was mainly performed with the aim of mimicking the recovery of basalt fibres from a pyrolysis treatment of composites at the end of their life. The results are summarised in Table 6. As shown, composites with basalt fibres treated in acetone followed by thermal treatment (TT) at $400{ }^{\circ} \mathrm{C}$ exhibited the lowest tensile strength and Young's modulus compared to acetone-treated and virgin basalt fibre reinforced composites. In particular, fibres treated only in acetone were not found to cause a reduction in mechanical properties compared to 
Table 6

Tensile properties of basalt fibre reinforced composites after sizing removal (TT means thermal treatment).

\begin{tabular}{lll}
\hline Sample & Young's modulus (GPa) & Tensile strength (MPa) \\
\hline HDPE10B & $2.65 \pm 0.40$ & $27.94 \pm 2.43$ \\
HDPE10B - acetone & $2.63 \pm 0.11$ & $29.63 \pm 2.52$ \\
HDPE10B - acetone + TT & $1.90 \pm 0.12$ & $23.90 \pm 0.21$ \\
HDPE10B5MA & $2.48 \pm 0.26$ & $34.40 \pm 2.09$ \\
HDPE10B5MA - acetone & $2.59 \pm 0.06$ & $35.95 \pm 0.82$ \\
HDPE10B5MA - & $2.22 \pm 0.10$ & $26.61 \pm 0.42$ \\
$\quad$ & & \\
acetone + TT & $5.07 \pm 1.07$ & $42.05 \pm 3.70$ \\
HDPE30B & $4.79 \pm 0.24$ & $41.20 \pm 2.48$ \\
HDPE30B - acetone & $3.92 \pm 0.44$ & $24.02 \pm 2.67$ \\
HDPE30B5MA & $5.26 \pm 0.26$ & $51.18 \pm 0.47$ \\
HDPE30B5MA - acetone & $4.48 \pm 0.04$ & $49.02 \pm 0.70$ \\
HDPE30B5MA - & $4.98 \pm 1.02$ & $34.63 \pm 2.27$ \\
$\quad$ acetone + TT & & \\
\end{tabular}

composites loaded with virgin fibres, thus suggesting an incomplete sizing removal, which is also confirmed by SEM analysis of the tensile fracture surfaces (Fig. 13a and b), where negligible differences compared to the untreated case can be observed. It is also an indirect observation of the limited effect of this solvent on the intrinsic properties of basalt fibres. On the contrary, fibres subjected to acetone and thermal treatment were characterised by a weaker interfacial adhesion (Fig. 14a and b) and a significant microscopic ductile behaviour of the matrix can be observed, due to a less effective action of basalt fibres in restraining matrix chain mobility. Composites with coupling agent showed better mechanical properties than the respective composites without coupling agent, which is ascribed to a higher level of interfacial adhesion with the matrix, as can be observed in Figs. 13(c and d) and 14 (c and d). The loss in mechanical properties experienced by composites reinforced with acetone + thermally treated fibres cannot be related therefore only to a weaker interfacial adhesion. It is suggested that a prolonged exposure to high temperatures degraded not only the sizing but also the intrinsic strength of basalt fibres, as confirmed by a recent study [50], thus resulting in lower tensile strength of composites. The loss in stiffness has instead to be ascribed to a more difficult fibre dispersion with increasing sizing removal, as a decrease in intrinsic Young's modulus of basalt fibres with thermal exposure is not likely to occur [50]. In conclusion, the treatment with acetone is not able to completely remove the sizing, as supported by surface and wetting properties of single basalt fibres reported in [20]. The results suggest the need to optimise the thermal treatment process of basalt fibres.

\section{Conclusions}

This experimental work reports on the thermal and mechanical properties of basalt, hemp and basalt/hemp fibre reinforced hybrid HDPE composites, with a view to broadening the industrial applications of natural fibre reinforced composites. Quantitative analysis of interfacial adhesion between commercial basalt fibres and HDPE revealed a non-optimal level of adhesion, which was significantly enhanced by incorporation of a maleated coupling agent. The same positive effects were observed also for hemp fibre composites, even though in both cases a decrease in crystallinity was detected which was effectively balanced by an improved fibre/matrix compatibility. Hybridisation with basalt fibres increased the tensile properties of hemp fibre composites, their overall crystallinity and Vicat softening temperature. Fibre length distribution in the composites demonstrated that basalt fibres undergo extensive breakage compared to hemp fibres and a mixture of hemp and basalt fibres brought about less damage to the respective fibres than the basalt-basalt and hemp-hemp interaction. All these results indicated that injection-moulded short hemp/basalt/HDPE hybrid composites resulted in enhanced performance that can be suitably exploited in semi structural applications.

In an attempt to recover basalt fibres from a pyrolysis treatment of composites at the end of their life, a sizing removal procedure consisting of an acetone extraction followed or not by a thermal exposure at $400{ }^{\circ} \mathrm{C}$ was investigated. The partial or complete sizing removal was

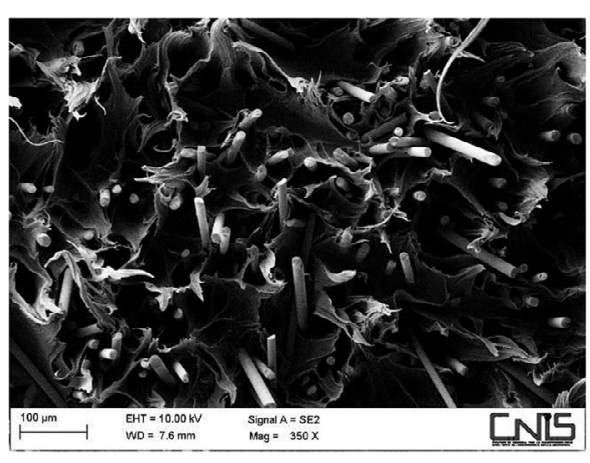

(a)

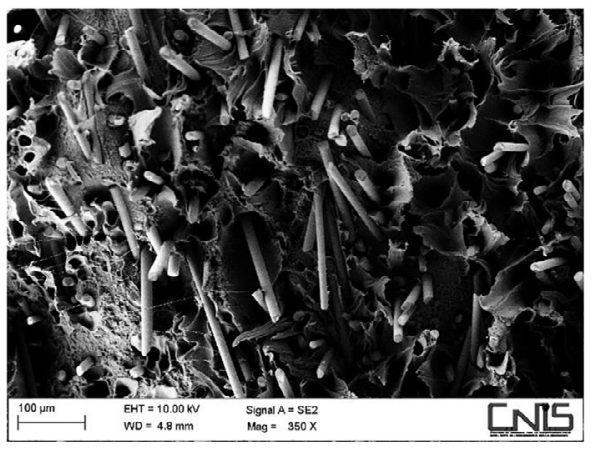

(c)

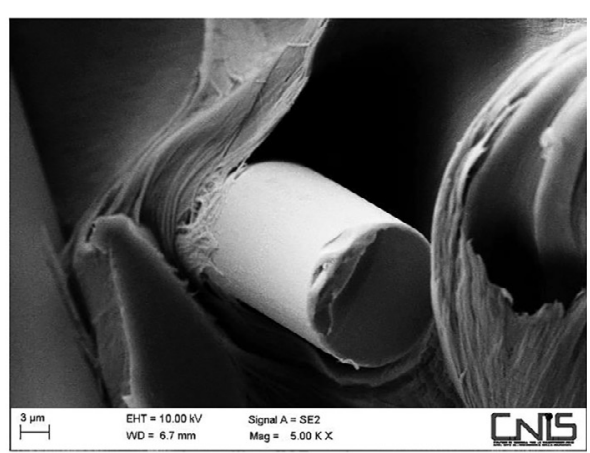

(b)

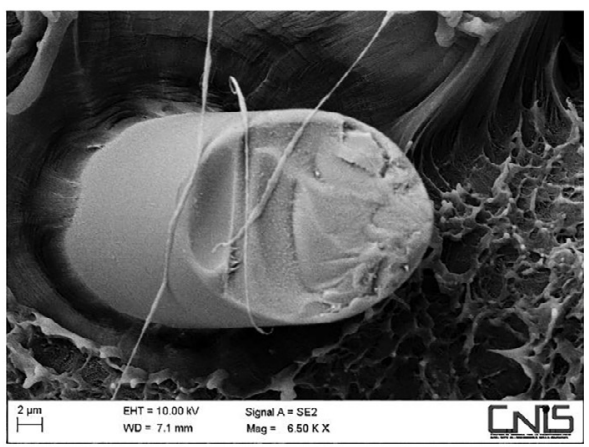

Fig. 13. SEM micrographs of tensile fracture surfaces of acetone-treated basalt/HDPE composites under different magnifications without (a-b) and (c-d) with coupling agent. 


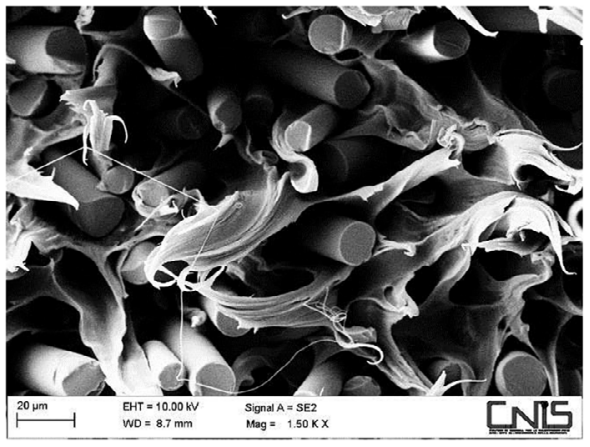

(a)

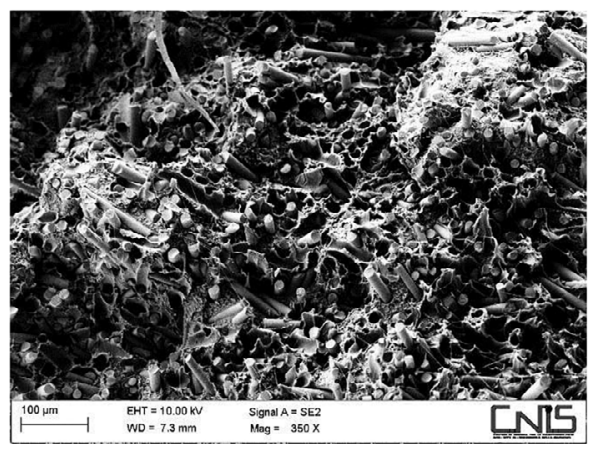

(c)

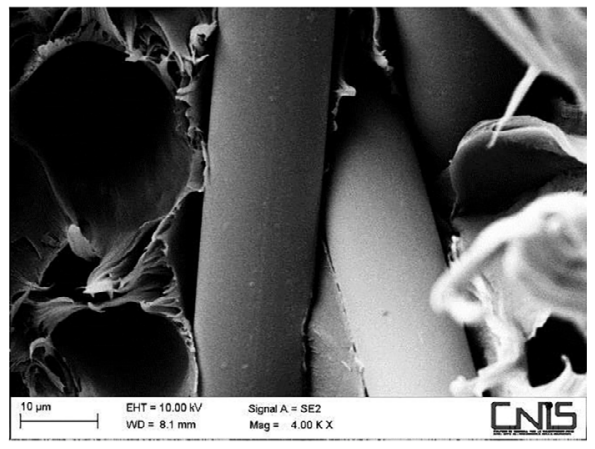

(b)

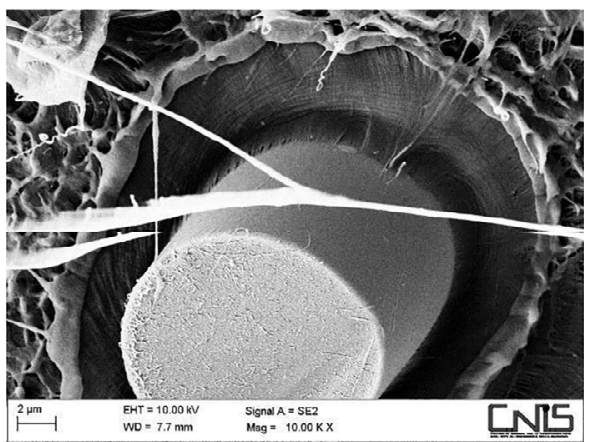

Fig. 14. SEM micrographs of tensile fracture surfaces of acetone + thermal treated (TT) basalt/HDPE composites under different magnifications without (a-b) and (c-d) with coupling agent. assessed by XPS and morphological investigations, while its effect on the mechanical properties of composites with and without coupling agent was elucidated. It was concluded that only a treatment with acetone is not able to completely remove the sizing and that the significant loss in tensile properties of composites reinforced with basalt fibres subjected to thermal exposure is due to a degradation of the intrinsic strength of basalt fibres along with poor dispersion of fibres inside the matrix. The results suggest the need to optimise the thermal treatment process of basalt fibres while providing details about the loss in mechanical properties that can be expected after a pyrolysis treatment at the end of life of composites reinforced with basalt fibres.

\section{References}

[1] Ashby MF. Materials and the environment: eco-informed material choice. Elsevier Inc.; 2009.

[2] Müssig J. Industrial application of natural fibres: structure, properties, and technical applications. Wiley; 2010.

[3] Pickering KL, Aruan Efendy MG, Le TM. A review of recent developments in natural fibre composites and their mechanical performance. Composites Part A 2016;83:98-112.

[4] Akampumuza O, Wambua PM, Ahmed A, Li W, Qin X. Review of the applications of biocomposites in the automotive industry. Polym Compos 2016.

[5] Lucintel. Global natural fiber composite market 2015-2020: trends, forecast, and opportunity analysis; 2015.

[6] Ford Motor Company. Sustainability Report 2015/16; 2016

[7] Swolfs Y, Gorbatikh L, Verpoest I. Fibre hybridisation in polymer composites: a review. Composites Part A 2014;67:181-200.

[8] Jawaid M, Abdul Khalil HPS. Cellulosic/synthetic fibre reinforced polymer hybrid composites: a review. Carbohydr Polym 2011;86:1-18.

[9] Fiore V, Scalici T, Di Bella G, Valenza A. A review on basalt fibre and its composites. Composites Part B 2015;74:74-94.

[10] Shahzad A. Hemp fiber and its composites - a review. J Compos Mater 2011;46:973-86.

[11] Lu N, Oza S. A comparative study of the mechanical properties of hemp fiber with virgin and recycled high density polyethylene matrix. Composites Part B 2013;45:1651-6.

[12] Lu N, Oza S. Thermal stability and thermo-mechanical properties of hemp-high density polyethylene composites: effect of two different chemical modifications. Composites Part B 2013;44:484-90.

[13] Ying Z, Wu D, Zhang M, Qiu Y. Polylactide/basalt fiber composites with tailorable mechanical properties: effect of surface treatment of fibers and annealing. Compos Struct 2017:176:1020-7.

[14] Karger-Kocsis J, Zhang Z, Czigány T. Special manufacturing and characteristics of basalt fiber reinforced hybrid polypropylene composites: mechanical properties and acoustic emission study. Compos Sci Technol 2006;66:3210-20.

[15] Szabó J, Czigány T. Static fracture and failure behavior of aligned discontinuous mineral fiber reinforced polypropylene composites. Polym Test 2003;22:711-9.

[16] Matkó S, Anna P, Marosi G, Szép A, Keszei S, Czigány T, et al. Use of reactive surfactants in basalt fiber reinforced polypropylene composites. Macromol Symp 2003;202:255-68.

[17] Zhang Y, Yu C, Chu PK, Lv F, Zhang C, Ji J, et al. Mechanical and thermal properties of basalt fiber reinforced poly(butylene succinate) composites. Mater Chem Phys 2012;133:845-9.

[18] Tabi T. Chopped basalt fibres: a new perspective in reinforcing poly(lactic acid) to produce injection moulded engineering composites from renewable and natural resources. eXPRESS Polym Lett 2012;7:107-19.

[19] Greco A, Maffezzoli A, Casciaro G, Caretto F. Mechanical properties of basalt fibers and their adhesion to polypropylene matrices. Composites Part B 2014;67:233-8.

[20] Pucci MF, Seghini MC, Liotier P-J, Sarasini F, Tirilló J, Drapier S. Surface characterisation and wetting properties of single basalt fibres. Composites Part B 2017;109:72-81.

[21] Graupner N, Rößler J, Ziegmann G, Müssig J. Fibre/matrix adhesion of cellulose fibres in PLA, PP and MAPP: a critical review of pull-out test, microbond test and single fibre fragmentation test results. Composites Part A 2014;63:133-48.

[22] Kelly A, Tyson WR. Tensile properties of fibre-reinforced metals: copper/tungsten and copper/molybdenum. J Mech Phys Solids 1965;13:329-38.

[23] Hesse R, Streubel P, Szargan R. Product or sum: comparative tests of Voigt, and product or sum of Gaussian and Lorentzian functions in the fitting of synthetic Voigt-based X-ray photoelectron spectra. Surf Interface Anal 2007;39:381-91.

[24] Murphy WR, Otterburn MS, Ward JA. Solvent recycling of polypropylene: 1 Properties of the recycled polymer. Polymer (Guildf) 1979;20:333-6.

[25] Wunderlich B, Cormier CM. Heat of fusion of polyethylene. J Polym Sci, Part A: Polym Chem 1967;5:987-8.

[26] Thomason JL, Dwight DW. XPS analysis of the coverage and composition of coatings on glass fibres. J Adhes Sci Technol 2000;14:745-64.

[27] Drzal LT, Madhukar M. Fibre-matrix adhesion and its relationship to composite mechanical properties. J Mater Sci 1993;28:569-610.

[28] Greco A, Maffezzoli A, Buccoliero G, Caretto F, Cornacchia G. Thermal and che mical treatments of recycled carbon fibres for improved adhesion to polymeric matrix. J Compos Mater 2013;47:369-77.

[29] Etcheverry M, Ferreira ML, Capiati NJ, Pegoretti A, Barbosa SE. Strengthening of polypropylene-glass fiber interface by direct metallocenic polymerization of propylene onto the fibers. Composites Part A 2008;39:1915-23.

[30] Torres FG, Cubillas ML. Study of the interfacial properties of natural fibre reinforced polyethylene. Polym Test 2005;24:694-8. 
[31] Herrera-Franco PJ, Valadez-Gonzalez A. A study of the mechanical properties of short natural fiber reinforced composites. Composites Part B 2005:36:597-608.

[32] Nahar S, Khan RA, Dey K, Sarker B, Das AK, Ghoshal S. Comparative studies of mechanical and interfacial properties between jute and bamboo fiber-reinforced polypropylene-based composites. J Thermoplast Compos Mater 2012;25:15-32.

[33] Chen J, Wang Y, Gu C, Liu J, Liu Y, Li M, et al. Enhancement of the mechanical properties of basalt fiber-wood-plastic composites via maleic anhydride grafted high-density polyethylene (MAPE) addition. Materials (Basel) 2013;6:2483-96.

[34] Fu S-Y, Mai Y-W, Lauke B, Yue C-Y. Synergistic effect on the fracture toughness of hybrid short glass fiber and short carbon fiber reinforced polypropylene composites. Mater Sci Eng, A 2002;323:326-35.

[35] Sarasini F, Tirillò J, Puglia D, Kenny JM, Dominici F, Santulli C, et al. Effect of different lignocellulosic fibres on poly( $\varepsilon$-caprolactone)-based composites for potential applications in orthotics. RSC Adv 2015;5:23798-809.

[36] Bledzki AK, Jaszkiewicz A. Mechanical performance of biocomposites based on PLA and PHBV reinforced with natural fibres - a comparative study to PP. Compos Sci Technol 2010;70:1687-96.

[37] Le Duigou A, Pillin I, Bourmaud A, Davies P, Baley C. Effect of recycling on mechanical behaviour of biocompostable flax/poly(l-lactide) composites. Composites Part A 2008;39:1471-8.

[38] Chin W-K, Liu H-T, Lee Y-D. Effects of fiber length and orientation distribution on the elastic modulus of short fiber reinforced thermoplastics. Polym Compos $1988 ; 9: 27-35$.

[39] Panthapulakkal S, Sain M. Injection-molded short hemp fiber/glass fiber-reinforced polypropylene hybrid composites-mechanical, water absorption and thermal properties. J Appl Polym Sci 2007;103:2432-41.

[40] Habibi Y, El-Zawawy WK, Ibrahim MM, Dufresne A. Processing and characterization of reinforced polyethylene composites made with lignocellulosic fibers from Egyptian agro-industrial residues. Compos Sci Technol 2008;68:1877-85.

[41] Joffre T, Miettinen A, Wernersson ELG, Isaksson P, Gamstedt EK. Effects of defects on the tensile strength of short-fibre composite materials. Mech Mater 2014;75:125-34.

[42] Keener T, Stuart R, Brown T. Maleated coupling agents for natural fibre composites. Composites Part A 2004;35:357-62.

[43] Pérez CJ, Alvarez VA, Stefani PM, Vázquez A. Non-isothermal crystallization of MaterBi-Z/clay nanocomposites. J Therm Anal Calorim 2007;88:825-32.

[44] Araújo JR, Waldman WR, De Paoli MA. Thermal properties of high density polyethylene composites with natural fibres: coupling agent effect. Polym Degrad Stab 2008;93:1770-5.

[45] Ludueña L, Vázquez A, Alvarez V. Effect of lignocellulosic filler type and content on the behavior of polycaprolactone based eco-composites for packaging applications. Carbohydr Polym 2012;87:411-21.

[46] Son S-J, Lee Y-M, Im S-S. Transcrystalline morphology and mechanical properties in polypropylene composites containing cellulose treated with sodium hydroxide and cellulase. J Mater Sci 2000;35:5767-78.

[47] Morin A, Dufresne A. Nanocomposites of Chitin Whiskers from Riftia tubes and Poly (caprolactone). Macromolecules 2002;35:2190-9.

[48] Namhata SP, Santolini L, Locati G. Rationalisation of Vicat softening point measurements. Polym Test 1990;9:75-89.

[49] Yu T, Ren J, Li S, Yuan H, Li Y. Effect of fiber surface-treatments on the properties of poly(lactic acid)/ramie composites. Composites Part A 2010;41:499-505.

[50] Sarasini F, Tirilló J, Seghini MC. Influence of thermal conditioning on tensile behaviour of single basalt fibres. Composites Part B 2017. 